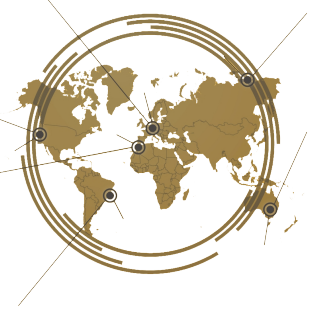

\title{
Self-directed learning in spoken grammar activities using poster presentation
}

\author{
Neni Marlina*, Nita Sari Narulita Dewi, Yusup Supriyono \\ English Education Department, Universitas Siliwangi, Tasikmalaya Indonesia
}

Looking for opportunities to let learners take charge of their learning autonomously is a pivotal responsibility for the teacher. This study aims at visualizing learners' self-directed learning in grammar in spoken discourse classroom through poster presentation. Poster presentations which are given to a small group repeatedly has contribution to cultivate not only their speaking opportunities but also self-directed learning, decision making, critical reflection, and independent action. A small group poster presenter consisting of 4 members is recruited as participants of the study. Learners' journals and a 45 minutevideo observation are analyzed using thematic analysis dealing with learners' self-directed learning. The findings reveal that through poster presentation, the learners' self-directed learning is portrayed as they select appropriate activities and strategies to present the material by searching from a number of resources, prepare their performance when they want to present, and handle questions or arguments from visitors. Those findings represents learners' self-motivation, self- responsibility, and also self-management in learning. This study provides information that the learners should be given opportunities to experience learning meaningfully that fosters their learning autonomy to achieve meaningful learning success.

Keywords: self-directed learning, grammar, poster presentation

\section{INTRODUCTION}

Teaching grammar in an oral context has received more attention nowadays. Unfortunately,

OPEN ACCESS ISSN 25033492 (online)

*Correspondence: Neni Marlina nenimarlina81@gmail.com

Received: 30th December 2019

Accepted: 9th June 2020

Published: 1st October 2020

Citation:

Marlina N, Dewi NSN and Supriyono Y (2020) Self-directed learning in spoken grammar activities using poster presentation.

J. Eng. Educ. Society. 5:2. doi: 10.21070/jees.v5i2.955 there are still many teachers teach grammar which focus more on written language. They have less attention on how grammar is used in spoken language. Although grammar in written and spoken language share a common core, there are significance differences regarding the structures among them. Grammar in spoken language has some specific characteristics such as that it is usually spontaneous and unplanned and produced in real time with no opportunity for editing (Cullen and chun Vicky Kuo, 2007). By looking at those specific characteristics, the appearance of fillers, backchannels, ellipsis, repetition, etc. could not be ignored.

The use of poster presentations was first introduced at scientific meetings in the 1970s and has since become a means popular for displaying information at conferences (Gosling, 1999) and currently, poster presentation has been proposed as a useful alternative strategy for class presentations (Lane, 2001; Lynch and Maclean, 1994; Tanner and Chapman, 2012). The benefits of poster presentations as learning strategies have been demonstrated in many studies, especially in teaching that facilitates learning. It has several contributions to learning achievement as an excellent alternative media for developing communication skills, involving learners in the 
assessment process, encouraging learners to investigate a topic thoroughly, providing opportunities for collaborative learning, promoting positive attitudes in learners, promoting creative thinking skills, critical, and reflective, as well as fostering learners' experience in solving problems and their independence.

Prichard and Ferreira (2014) found that poster presentations, which were given repeatedly to small groups, had several advantages, including increased speaking opportunities, increased interaction between speakers and audience, and reduced speaker anxiety. Furthermore, because of repetition, this can improve language skills. Research shows that repetition can help improve fluency and retention of new vocabulary and grammatical structures.

Previous research has shown that the use of poster presentations has many benefits for language learners to practice the language they are learning while presenting topics. Tanner and Chapman (2012) argue that people learn language not by making language the object of study, but rather "experience it as a medium of communication" in the context of "real operating conditions". Using poster presentations, learners are encouraged to use language especially spoken English grammar that they learn while presenting material to the audience. In line with Tanner and Chapman (2012) Ozturk (2017) states that poster presentations help learners work collaboratively in groups, overcome anxiety and gain more confidence during presentations. As well as increasing creativity, promoting selfdirected learning, and inspiring learners for their future teaching careers.

As previously stated, poster presentations have many benefits not only to improve the learners' cognitive skills, but it also promotes learners' self- directed learning (Ozturk, 2017). Self-directed learning is one of the key factors that support student success in the learning process. In self-learning (SDL), learners take the initiative and responsibility for what happens, they choose, manage, and assess their own learning activities, which can be done anytime, anywhere, in any way, at any age. Self-directed learning describes a process in which individuals take the initiative, without the help of others, in diagnosing their learning needs, formulating learning goals, identifying human resources and materials for learning, choosing and implementing appropriate learning strategies, and evaluating learning outcomes Knowles (1975).

Poster presentations facilitate learners to encourage their self-directed learning in learning grammar in spoken discourse through assignments where they must plan, find, and select evidence, monitor their progress, assess the quality of their own work, work effectively with others, use evidence to reach conclusions, and present information. In addition, poster presentations that were given repeatedly to small groups gave them several advantages to improve their speaking skills, improve their performance and interaction with the audience, and overcome the anxiety they felt during the presentation (Prichard and Ferreira, 2014). In learning oral grammar, poster presentations are assumed to provide opportunities for learners to practice oral grammar features in real situations to become more aware of the nature of spoken language and to improve their speaking abilities. This activity suggested meaningful interaction and show high quality of learning performances which is appropriate higher education learners (Dewi et al., 2019).

The purpose of this paper is to explain the potentials associated with using poster presentations in Grammar in Spoken Discourse class focusing on the learners' self-directed learning. The following research question in this study is: "How is the learners' self-directed learning in spoken grammar activities using poster presentation?".

\section{METHOD}

This study adopted a case study to investigate the learners' selfdirected learning in a Grammar in Spoken Discourse subject when they utilized poster to convey the materials they had to present to audience/visitors. The process of investigating learners' self-directed learning was not seen only when they presented in the classroom, but also when they got themselves to prepare the materials and the poster. The process of spoken grammar learning through poster presentation is depicted in Figure 1.

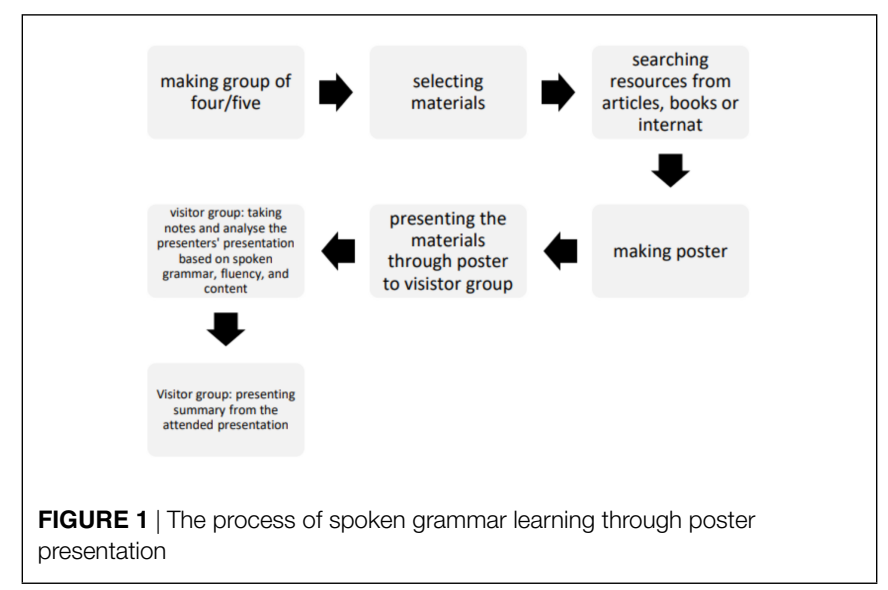

\section{Participants and Setting}

This study involved four learners from a small group poster presenter consisting of two members in Spoken Grammar classroom and other two members from them who were as visitors. The participants of this study were the second semester of English education learners in the average age of 19 years old. They joined Grammar in Spoken Discourse subject as one of the subjects as the continuation of Grammar in Written Discourse subject which intended to facilitate them to learn grammar not only in written context but also in spoken context to build their knowledge and awareness of the difference of written and spoken grammar.

Spoken Grammar classroom facilitates the learners to learn characteristics and features of spoken grammar which are different from the written grammar. This subject serves the learn- 
ers to learn spoken grammar as much as three credits in a week. The participants learned grammar in spoken discourse through poster presentation in which they were divided into small groups consisting four members. They had to present the materials using posters with difference topic to present to the audience or visitors. The difference between presentation using poster and without is that the learners in poster presentation should present the materials to each small group/visitors. Once presentation had four groups to present the materials.

\section{Data Collection and Procedure}

To gain data to investigate the learners' self-directed learning, this study used learners' journals of spoken grammar and observation. After conducting poster presentation, the learners were asked to write their daily journal to express their learning experience through poster presentation. They described what and how they learned, experienced and felt, what obstacles they found, how they coped their obstacles and how the project helped them improve their speaking ability. Meanwhile, observation was used to investigate their process they presented the materials through poster presentation.

The observation was done through a 45-minute video recording to generate how their self-directed learning during conducting poster presentation emerged. This recording described the participants who were conducting the materials through poster presentation to three groups of visitors. They had to present their materials related to the subject of spoken grammar as long as fifteen minutes to each visitor. The stages of learning process through poster presentation is explained inTable 1.

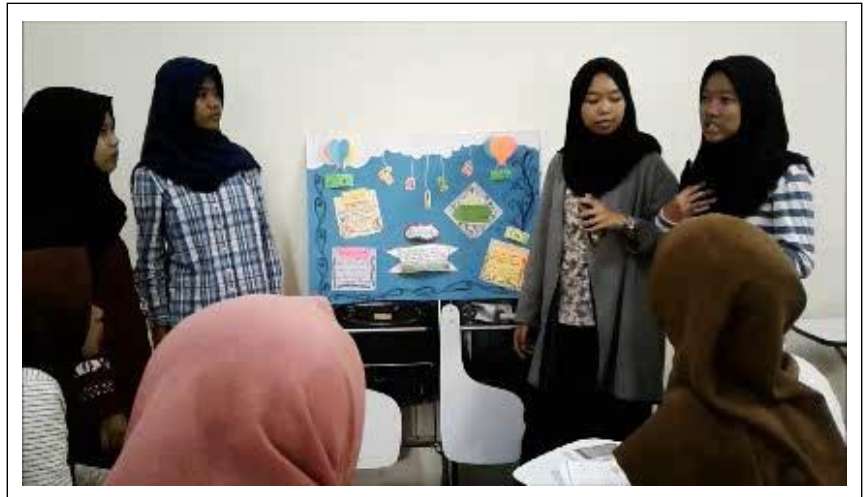

FIGURE 2 | Students' presentation through poster

\section{Data Analysis}

The data gained from learners' journals and a 45 -video recording were analysed by using thematic analysis consisting of six steps; familiarizing with the data, generating initial codes, searching for themes, reviewing themes, defining and naming themes, and producing the report. Thematic analysis is defined as to determine, analyze, and report the themes within the data (Braun and Clarke, 2006). This analysis instrument helped the researchers to analyse the data and to find the answer of this research. Before analysing the data, the researchers needed to transcribe the spoken data from video recording into a written one to ease the researchers to identify the findings.

\section{FINDINGS AND DISCUSSION}

Data from learners' journals and their video recording reveal that the use of poster presentation has emerged the learners' self-directed learning in learning spoken grammar. This section goes on to look at the learners' self- directed learning when they learned spoken grammar using poster presentation. Poster presentation has already facilitated the learners to learn independently. Each member of the group of poster presenters received responsibility to fulfill their learning standard. There are some findings when the learners experienced themselves in learning Spoken grammar through poster presentation.

\section{Learners' Learning Motivation}

Learners' Self-directed learning when learning Grammar in Spoken Discourse using poster presentations is illustrated from their learning motivation during attending this course, especially when they make presentations through posters. Learners seemed enthusiastic about participating in the activity because they experienced learning that was different from normal learning. The learners' motivation appears through from their enthusiasm of those who were as presenters (presenter) in the form of looking for information/materials that would be delivered to the audience by looking for it from various sources such as the internet, books, and choosing the right strategy to deliver the materials. Besides, the learners read literature and discussed to understand the material that would be delivered with the group member.

From the audience (visitors) who visited the group presentations, they were enthusiastic listening to the presentations of the presenters. They also did not hesitate to ask if there were things they did not understand about the topic presented. They also did not hesitate to provide input or add information to their friends who were presenting if there was anything they knew about the topic.

"I searched many references on the internet and I also asked my lecturer about the references that would be presented by my group. There were some difficulties and confusing materials that we faced, but we discussed and made summary. After understanding the material, we made a unique poster to attract the audience to the topic presented"

student 1

"I prepare myself by reading references from several sources. To understand this, I read 
TABLE 1 | Stages of learning through poster presentation

$\begin{array}{ll}\text { Stages } & \text { Activities } \\ 1 & \text { The students are divided into } 12 \text { groups consisting of } 4-5 \text { students each. In this stage each group chooses } \\ & \text { one topic to be } \\ \text { presented in the next weeks. } & \text { Each group should search the resources from the articles, journals, books, or any other resources. After } \\ & \text { getting the materials, they present it in poster. } \\ & \text { Each week, there will be three groups presenting different } \\ & \text { materials. Each group will present the materials for three times to different visitor groups during the meet- } \\ & \text { ing. (see Figure 2 ) } \\ & \text { Each visitor group during attending the presentation is divided to be note takers and analysts. Note takers } \\ \text { are responsible to take notes during presentation, and analysts examine the presenters' spoken grammar, } \\ \text { fluency, and presentation content. } \\ \text { Visitor groups are not only listen to what the presenters present, but also they evaluate their partners } \\ \text { during their presentation. } \\ \text { After presentation, visitor groups report what they have already obtained and compare information they } \\ \text { got from each visitor group. }\end{array}$

and outlined to make it easier for me to remember for longer periods of time."

\section{student 2}

"Today I as a visitor saw the groups who presented their materials through posters. We listened to their presentation even though there were some things that were confusing and did not understand, but because the presenters are our friends, so I dared to try asking questions to clarify the materials presented until I understood what was said."

student 3

From the data, learners' activities by looking for sources, conducting discussion with their group members or classmates, trying to understand the materials by making a summary, showing the willingness of learners to learn which is indicated as learning motivation. Motivation is one indicator that is very important for the learners' success in learning. Motivation is a complex psychological social influence that sets to accelerate the will of a person towards a desire. In this case, the use of poster presentations in the learning process motivates learners to complete assignments through a series of activities mentioned above. Sunumlarin et al. (2017) states that poster presentations have many benefits in addition to improving language skills as well as increasing motivation, self-confidence, and the ability to work together. Furthermore, if posters can generate learners' interest, then it fosters learners' self-directed learning Cetin and Flamand (2013).

\section{Learners' Self-Responsibility}

The form of other self-directed learning shown by learners in Grammar in Spoken discourse is through the existence of their self-responsibility or individual/personal responsibility. The following data were obtained from learners' reflective journals.

"The first thing I did was look for and discuss the material to be delivered on the poster with my group. I try to understand hard about the topic and when there are things I don't know I ask friends in my group."

student 1

"As a visitor, I tried hard to pay attention to the materials delivered by my friends who were presenting. Sometimes the explanation was not very clear because it was noisy with other group presentations, but we could ask the presenters to repeat their explanation."

student 4

Even from observational data, the form of their responsibilities is seen. They helped each other, such as, when one of their friends was doing presentation, and he was confused to explain or answer questions. This shows that they had an awareness of their responsibilities as individuals and as a team that should contribute or support for the success of their team so that by recognizing the responsibilities they carry, they can recognize their learning needs, choose better ways of learning, and evaluate the learning results (Lai et al., 2013).

\section{Learners' Self-Management}

The third finding from this study is that the use of posters has really helped learners develop their learning potential well. Self-management or self-organizing to learn is a form of selfdirected learning for learners who took part in learning with 
posters. How to prepare the necessary resources, understand the material to be delivered, plan and make posters that meet the established criteria and be able to attract visitors to listen to their presentations, handle all obstacles that occur before and when making presentations is a form of their self-management during learning with a poster.

"I prepared myself by reading references from several sources. To understand this, I read and outlined to make it easier for me to remember for longer periods of time. I handled my difficulties when I had to present materials by trying to be confident."

student 4

"I tried to get audience's attention by giving jokes during the presentation. I also tried not to be nervous by holding my hands and taking deep breath before and during the presentation."

student 5

"To practice presenting the material, I learned from my friend's presentation (the presentation of other groups) how to speak clearly, control our volume, and how to make other people understand our explanations easily."

student 6

"I saw my audience. If they had good mood or listened carefully, I presented my topic in detail and added a few points. If my audience looked boring, I would speed up my presentation and made it simpler. To manage time well, I also asked the videographer to warn me if the time had run out, so we know when to stop explaining the material."

student 7

The data explained that they tried to organize themselves to be able to overcome all the circumstances that occurred during the presentation with the poster. They tried to understand the materials in various ways that they thought those would be appropriate, prepared themselves to present the material, overcame all obstacles such as worry or nervousness, as well as circumvent the presentation to be more effective and efficient, a form of self- management that learners have done. In

\section{REFERENCES}

Braun, V. and Clarke, V. (2006). Using thematic analysis in psychology. Qualitative Research in Psychology.

Cetin, Y. and Flamand, L. (2013). Posters, self-directed learning, and L2 vocabulary this case the poster presentation contributes not only to their achievements but to their positive attitude. (Tanner and Chapman, 2012). They have a way to solve their own problems so it gives them an opportunity to be able to determine their learning styles.

The three findings show that the use of poster presentations in the language classroom, especially in Grammar in Spoken Discourse subject provides many contributions such as the learning process that emphasizes student- centered learning, learning by doing experience where learners apply the principles of grammar in the spoken discourse directly through the presentation process, and most importantly in the focus of this research learners' self-directed learning emerges through this activity.

\section{CONCLUSIONS AND SUGGESTIONS}

The results of this study have identified the forms and how selfdirected learning of learners when learning grammar in spoken discourse using poster presentations. The results of reflective journals and observations show that poster presentations have fostered learners' self-directed learning during learning that is seen from their learning motivation, individual responsibility for completing assignments as well as possible, and their selfmanagement process in dealing with each obstacle also determines how to learn the right one according to their needs.

This research has shown that facilitating learners to learn more independently is a requirement for every lecturer so that they can experience learning and achieve more meaningful learning success. This research only focuses on the picture of learners' self-directed learning when learning, there are still many aspects that need to be explored besides self-directed learning. The authors suggest the use of poster presentations should continue to be used and developed in order to provide many benefits for learners. In addition, as mentioned previously, the use of poster presentations not only contributes to the growth of self-directed learning, so researchers are further advised to explore the opportunities and challenges that arise from the use of poster presentations.

\section{ACKNOWLEDGMENTS}

This research project was fully funded by the Universitas Siliwangi, Tasikmalaya. We are grateful to the university and to the participants who volunteered to participate in the research project. acquisition. ELT Journal 67, 52-61. doi: 10.1093/elt/ccs053.

Cullen, R. and chun Vicky Kuo, I. (2007). Spoken Grammar and ELT Course Materials: A Missing Link? TESOL Quarterly 41, 361-386. doi: 10.1002/j.1545-7249. 2007.tb00063.x.

Dewi, N. S. N., Marlina, N., and Supriyono, Y. (2019). The Quest of Self- Directed 
Learning of Adult EFL Learners in Indonesian Higher Education Context.

Gosling, P. J. (1999). Scientist's guide to Poster Presentations (New York: Springer Science and Business Media).

Knowles, M. (1975). Self-directed learning (Association Press).

Lai, C., Gardner, D., and Law, E. (2013). New to facilitating self-directed learning: the changing perceptions of teachers. Innovation in Language Learning and Teaching 7, 281-294. doi: 10.1080/17501229.2013.836208.

Lane, K. (2001). Promoting posters. In PAC 3 at JALT2001 Conference Proceedings (Japan Association of Language Teachers), 287-287.

Lynch, T. and Maclean, J. (1994). Poster carousel. In New ways of teaching speaking, eds. K. Bailey and L. Savage (TESOL), 108-109.

Ozturk, O. (2017). Using Poster Presentation to Facilitate EFL Teacher Learning. International Journal of Language Academy, 401-415.

Prichard, C. and Ferreira, D. (2014). The Effects of Poster Presentations and Class Presentations on Low-Proficiency Learners. TESOL Journal 5, 172-185. doi: $10.1002 /$ tesj.131.

Sunumların, P., Öğretmen, İ., Öğrenme, A., Kolaylaştırıcı, S., Kullanılması, O., and
Öztürk, Ö. (2017). International Journal of Language Academy USING POSTER PRESENTATIONS TO FACILITATE.

Tanner, P. and Chapman, J. (2012). Poster presentations speak for themselves. doi: 10.37546/jalttlt36.3-3. https://dx.doi.org/10.37546/jalttlt36.3-3.

Conflict of Interest Statement: The authors declare that the research was conducted in the absence of any commercial or financial relationships that could be construed as a potential conflict of interest.

Copyright (C) 2020 Marlina, Dewi and Supriyono. This is an open-access article distributed under the terms of the Creative Commons Attribution License (CC BY). The use, distribution or reproduction in other forums is permitted, provided the original author(s) and the copyright owner(s) are credited and that the original publication in this journal is cited, in accordance with accepted academic practice. No use, distribution or reproduction is permitted which does not comply with these terms. 